\title{
Power systems with high renewable energy sources: A review of inertia and frequency control strategies over time
}

\author{
Ana Fernández-Guillamón ${ }^{\mathrm{a}}$, Emilio Gómez-Lázaro ${ }^{\mathrm{b}}$, Eduard Muljadi ${ }^{\mathrm{c}}$, Ángel Molina-García ${ }^{\mathrm{a}}$ \\ a Dept. of Electrical Engineering, Universidad Politécnica de Cartagena, 30202 Cartagena, Spain \\ ${ }^{\mathrm{b}}$ Renewable Energy Research Institute and DIEEAC-EDII-AB, Universidad de Castilla-La Mancha, 02071 Albacete, Spain

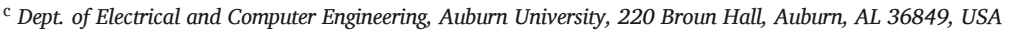

\section{A R T I C L E I N F O}

\section{Keywords}

Inertia constant

Power system stability

Frequency regulation

Damping factor

Renewable energy sources

Virtual inertia

\begin{abstract}
A B S T R A C T
Traditionally, inertia in power systems has been determined by considering all the rotating masses directly connected to the grid. During the last decade, the integration of renewable energy sources, mainly photovoltaic installations and wind power plants, has led to a significant dynamic characteristic change in power systems. This change is mainly due to the fact that most renewables have power electronics at the grid interface. The overall impact on stability and reliability analysis of power systems is very significant. The power systems become more dynamic and require a new set of strategies modifying traditional generation control algorithms. Indeed, renewable generation units are decoupled from the grid by electronic converters, decreasing the overall inertia of the grid. 'Hidden inertia', 'synthetic inertia' or 'virtual inertia' are terms currently used to represent artificial inertia created by converter control of the renewable sources. Alternative spinning reserves are then needed in the new power system with high penetration renewables, where the lack of rotating masses directly connected to the grid must be emulated to maintain an acceptable power system reliability. This paper reviews the inertia concept in terms of values and their evolution in the last decades, as well as the damping factor values. A comparison of the rotational grid inertia for traditional and current averaged generation mix scenarios is also carried out. In addition, an extensive discussion on wind and photovoltaic power plants and their contributions to inertia in terms of frequency control strategies is included in the paper.
\end{abstract}

$\begin{array}{ll}\text { Nomenclature } \\ \text { DFIG } & \text { Double Fed Induction Generator } \\ \text { EU } & \text { European Union } \\ \text { FSWT } & \text { Fixed Speed Wind Turbine } \\ \text { HAWT } & \text { Horizontal Axis Wind Turbine } \\ \text { PMSG } & \text { Permanent Magnet Synchronous Generator } \\ \text { PV } & \text { Photovoltaic } \\ \text { RES } & \text { Renewable energy sources } \\ \text { ROCOF } & \text { Rate Of Change Of Frequency } \\ \text { SCIG } & \text { Squirrel Cage Induction Generator } \\ \text { VSWT } & \text { Variable Speed Wind Turbine } \\ \text { WPP } & \text { Wind Power Plant }\end{array}$

\section{Introduction}

Presently, power system stability relies on synchronous machines connected to the grid. They are synchronized to the grid and their stored kinetic energy is automatically extracted in response to a sudden power imbalance. For example, a sudden additional large load or a loss of a large generation unit from the grid, will slow down the machines on the grid and subsequently reduce grid frequency [1]. However, the power systems generation fleet is changing from conventional generation to renewable energy sources (RES) [2]. Limited fossil fuel reserves and the importance of reducing greenhouse gases emissions are the main reasons for this transition in the electrical generation [3]. For instance, wind, solar and biomass generations overtook coal power in the EU for the first time during the year 2017 [4]. However, some authors consider that only half of the overall electricity demand can be provided by RES $[5,6]$, despite the fact that it is expected that future electrical grids will be based on RES, distributed generation and power electronics [7]. As an example, in Europe, it is expected that 323 and $192 \mathrm{GW}$ of wind and PV will be installed in 2030, which will cover up to $30 \%$ and $18 \%$ of the demand, respectively $[8,9]$.

Among the different renewable sources available, PV and wind (especially doubly fed induction generators, DFIG [10]) are the two most promising resources for generating electrical energy [11]. Apart from their intermittency, they are connected through power convert-

\footnotetext{
Corresponding author.

E-mail addresses: ana.fernandez@upct.es (A. Fernández-Guillamón); emilio.gomez@uclm.es (E. Gómez-Lázaro); mze0018@auburn.edu (E. Muljadi); angel.molina@upct.es (Á. Molina-García)
} 
ers which decouple them from the power system grid $[12,13]$. Therefore, the effective inertia of the electrical grid is reduced when conventional generators are replaced by RES $[14,15]$, affecting the system stability and reliability [16]. This fact is considered as one of the main drawbacks of integrating a large amount of non-synchronous generators (i.e. RES) into the grid [17], as the frequency stability and its transient response is compromised [18]. Actually, low system inertia is related with $(i)$ a faster rate of change of frequency (ROCOF) and (ii) larger frequency deviations (lower frequency nadir during frequency dips) within a short-time frame [19].

In this work, we conduct an extensive literature review focusing on the inertia values for power systems and wind power plants. The averaged inertia values are estimated by different countries for the last two decades, by considering the 'effective' rotating masses directly connected to the grid. In addition, the damping factor evolution is also included in the paper based on most of technical contributions and analysis found in the literature. The rest of the paper is organized as follows: inertia and damping factor analysis for power systems is discussed in detail in Section 2, determining the averaged inertia estimation for different countries; control strategies and contributions to integrate RES into grid frequency response is described in Section 3; finally, the conclusion is given in Section 4 .

\section{Inertia analysis in power systems}

\subsection{Modeling the inertial response of a rotational synchronous generator: inertia constant analysis}

The group turbine-synchronous generator rotates due to two opposite torques: ( $i$ ) mechanical torque of the turbine, $T_{m}$ and (ii) electromagnetic torque of the generator, $T_{e}$. The motion equation is $[20,21]$ :

$2 H \frac{d \omega_{r}}{d t}=T_{m}-T_{e}$,

where both the $T_{m}$ and the $T_{e}$ are expressed in pu and $H$ the inertia constant in $\mathrm{s} . H$ is given by:

$H=\frac{1}{2} \cdot \frac{J \cdot \omega_{\text {base }}^{2}}{S_{\text {base }}}$,

being $J$ the moment of inertia, $\omega_{\text {base }}$ the base frequency and $S_{\text {base }}$ the base power. $H$ determines the time interval during which the generator can supply its rated power only using the kinetic energy stored in the rotational masses of the generator. In Table 1, a review of $H$ values for different types of generation units and rated power is shown.

Expressing Eq. (1) in terms of power, and considering the initial status as $0, P=P_{0}+\Delta P=\left(\omega_{r 0}+\Delta \omega_{r}\right) \cdot\left(T_{0}+\Delta T\right)$. For small deviations, the second order terms are neglected due to their small values, thus $\Delta P \simeq \omega_{r 0} \cdot \Delta T+T_{0} \cdot \Delta \omega_{r}$, being $\Delta P=\Delta P_{m}-\Delta P_{e}$ and $\Delta T=\Delta T_{m}-\Delta T_{e}$. Furthermore, in steady-state $T_{m 0}=T_{e 0}$ and $\omega_{r 0}=1 \mathrm{pu}$. Hence, $\Delta P=\Delta P_{m}-\Delta P_{e} \simeq \Delta T_{m}-\Delta T_{e}$.

Therefore, if small variations around the steady-state conditions are considered, Eq. (1) can be written as Eq. (3) in the time domain, or as Eq. (4) if the Laplace transform is applied.

$\frac{d \Delta \omega_{r}}{d t}=\frac{1}{2 H}\left(\Delta P_{m}-\Delta P_{e}\right)$

$\Delta \omega_{r}=\frac{\Delta P_{m}-\Delta P_{e}}{2 H \cdot s}$

Some loads (especially inverter-based loads) can also be modified to work as a load resource (demand response capability) under frequency deviations (e.g., motors driving compressors, pumps, industry loads, HVAC-heating ventilation air conditioning ...). This fact can be modeled by including the damping factor $D$. As an example, for a synchronous machine, the electrical power $P_{e}$ can be then expressed as follows,
Table 1

Summary of inertia values $(H)$ for different generation types.

\begin{tabular}{lllll}
\hline Type of generating unit & Rated power & $H(\mathrm{~s})$ & Reference & Year \\
\hline Thermal & $500-1500 \mathrm{MW}$ & $2.3-2$ & {$[22]$} & 2008 \\
Thermal & $1000 \mathrm{MW}$ & $4-5$ & {$[23]$} & 2011 \\
Thermal & $10 \mathrm{MW}$ & 4 & {$[24]$} & 2007 \\
Thermal & Not indicated & $4-5$ & {$[25]$} & 2012 \\
Thermal (2 poles) & Not indicated & $2.5-6$ & {$[26]$} & 1994 \\
Thermal (4 poles) & Not indicated & $4-10$ & {$[26]$} & 1994 \\
Thermal (steam) & $130 \mathrm{MW}$ & 4 & {$[12]$} & 2012 \\
Thermal (steam) & $60 \mathrm{MW}$ & 3.3 & {$[12]$} & 2012 \\
Thermal (combined cycle) & $115 \mathrm{MW}$ & 4.3 & {$[12]$} & 2012 \\
Thermal (gas) & $90-120 \mathrm{MW}$ & 5 & {$[12]$} & 2012 \\
Thermal & Not indicated & $2-8$ & {$[27]$} & 2011 \\
Hydroelectric $450<n<514 \mathrm{rpm}$ & $10-65 \mathrm{MW}$ & $2-4.3$ & {$[22]$} & 2008 \\
Hydroelectric $200<n<400 \mathrm{rpm}$ & $10-75 \mathrm{MW}$ & $2-4$ & {$[22]$} & 2008 \\
Hydroelectric $138<n<180 \mathrm{rpm}$ & $10-90 \mathrm{MW}$ & $2-3.3$ & {$[22]$} & 2008 \\
Hydroelectric $80<n<120 \mathrm{rpm}$ & $10-85 \mathrm{MW}$ & $1.75-3$ & {$[22]$} & 2008 \\
Hydroelectric & Not indicated & 4,75 & {$[28]$} & 2013 \\
Hydroelectric $n<200 \mathrm{rpm}$ & Not indicated & $2-3$ & {$[29]$} & 1994 \\
Hydroelectric $n>200 \mathrm{rpm}$ & Not indicated & $2-4$ & {$[29]$} & 1994 \\
Hydroelectric & Not indicated & $2-4$ & {$[26]$} & 1994 \\
\hline
\end{tabular}

$\Delta P_{e}=\Delta P_{L}+D \cdot \Delta \omega_{r}$

where $P_{L}$ represents the load independent from frequency excursions.

Substituting Eq. (5) into Eq. (4), the mathematical representation of the motion of a synchronous generator is obtained. It is commonly referred to as swing equation, see Eq. (6). It can be expressed in the form of a block diagram as shown in Fig. 1. Hence, the initial response of a synchronous generator to a frequency event is governed by its stored kinetic energy at the rated frequency [30],

$\Delta \omega_{r}=\frac{\Delta P_{m}-\Delta P_{L}}{2 H \cdot s+D}$

\subsection{Aggregated swing equation: equivalent inertia constant and damping factor analysis}

In order to apply the swing equation to a power system, Eq. (6) is rewritten. All synchronous generators are reduced to an equivalent rotating mass with an equivalent inertia $H_{e q}$,

$H_{e q}=\frac{\sum_{i=1}^{G C P S} H_{i} \cdot S_{\text {base }, i}}{S_{\text {base }}}$

being GCPS the number of generators coupled to the power system [31], such as conventional power plants and FSWTs. In the past, it was considered that the equivalent inertial constant $H_{e q}$ of a power system was constant and time-independent. However, due to the RES integration and the variation in their generation throughout the day, the season of the year, etc., it is understood that $H_{e q}$ changes with time. An example of this variation is presented for the German power system during 2012 in Ref. [32], see Fig. 2. From these data, the cumula-

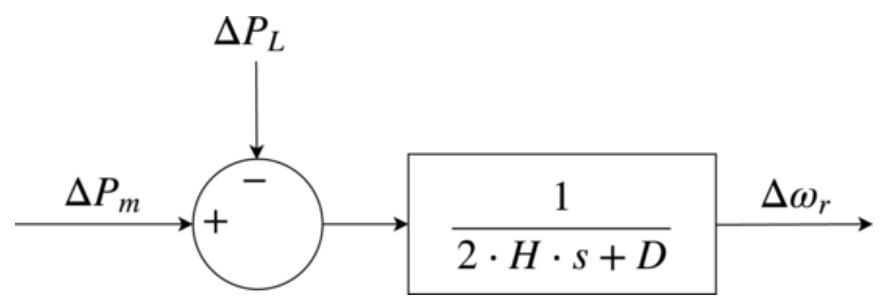

Fig. 1. Block diagram representation of the swing equation. 


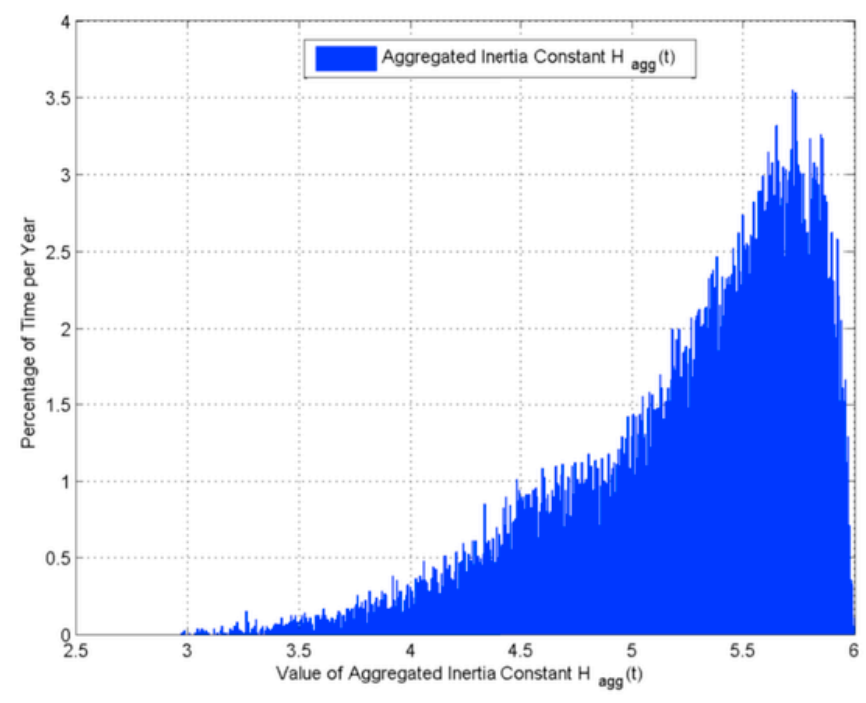

Fig. 2. Histogram of equivalent inertia $H_{e q}$ in the German power system during 2012 [32].

tive frequency curve is obtained and depicted in Fig. 3. It can be seen that during $50 \%$ of the year 2012, the equivalent inertia was under $5.7 \mathrm{~s}$; $10 \%$ of the year, $H_{e q}$ was under $5 \mathrm{~s}$; and only $1 \%$ of the year, its value was under $4 \mathrm{~s}$.

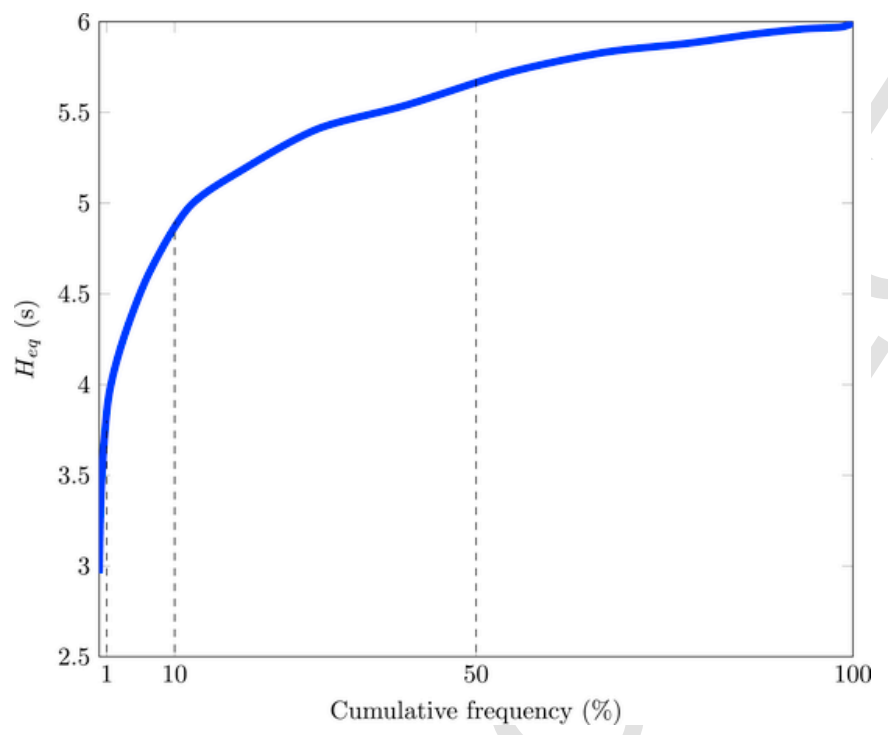

Fig. 3. Cumulative frequency of the equivalent inertia $H_{e q}$ in the German power system during 2012.
Table 2

Damping factor values. Literature review.

\begin{tabular}{llll}
\hline & $\begin{array}{l}\text { Value }( \\
\left.p u_{M W} / p u_{H z}\right)\end{array}$ & Analysis & Year \\
\hline Ref. & $1-2$ & Power system stability & 1994 \\
{$[26]$} & $1-2$ & Two areas with non-reheat thermal units & 2011 \\
{$[35]$} & 0.83 & Two areas with thermal units & 2011 \\
{$[36]$} & 1.66 & Three areas with non-reheat thermal units & 2012 \\
{$[37]$} & $1-1.8$ & One area with nuclear, thermal, wind and PV & 2012 \\
{$[38]$} & 2 & Three areas with non-linear thermal units & 2013 \\
{$[39]$} & $0.5-0.9$ & Two areas non-reheat thermal units & 2013 \\
{$[40]$} & 0.83 & Two areas with thermal units & 2013 \\
{$[41]$} & 0.83 & Two areas with reheat units & 2015 \\
{$[42]$} & 0.83 & IEEE 9 bus system with hydro-power, gas and & 2016 \\
{$[43]$} & 0.8 & wind turbines & \\
& & One and three areas with non-reheat thermal & 2017 \\
{$[44]$} & $1-1.8$ & units & \\
& & Three areas with non-reheat thermal units & 2018 \\
{$[45]$} & $1-1.8$ & Two areas with non-reheat thermal units & 2018 \\
{$[46]$} & 1 & &
\end{tabular}

In the same way as synchronous generators, all loads are grouped in an equivalent one with an equivalent damping factor $D_{e q}$. As stated in Ref. [33], the impact of an inaccurate value of $D_{e q}$ is relatively small if the power system is stable, but this can be a major contribution under disturbances. Moreover, it is expected to decrease accordingly to the use of variable frequency drives [34]. Table 2 summarizes the different values proposed for the damping factor in the literature over recent decades.

By using Eq. (7), an estimation of the equivalent inertia $H_{e q}$ of several parts of the world has been carried out by the authors. The International Energy Agency (IEA) provides global statistics about energy [47]. By considering the annual averaged electricity, an averaged equivalent inertia constant $\left(H_{e q}\right)$ provided by such conventional power plants -Table 1 - can be estimated. Note that for this estimation, $S$ of Eq. (7) is replaced by the annual electricity value $\left(E_{g}\right)$. The expression used to estimate the inertia is then Eq. (8), being $E_{g, t o t a l}$ the total electricity supplied (conventional + RES generation) within a year.

$H_{e q}=\frac{\sum_{i=1}^{G C P S} H_{i} \cdot E_{g, i}}{E_{g, t o t a l}}$.

Fig. 4 shows a significant change in the averaged generation mix between 1996 and 2016. The total electricity consumption has been increased by more than $80 \%$ within these two decades. However, RES generation has only increased by $4 \%$ in the same two decades. Moreover, the share of the different renewable sources has changed significantly. Indeed, the contribution share from hydro-power has been surpassed by biomass, biofuels, wind, and PV. Based on the approach previously described, Fig. 5 depicts the differences between the inertia constant for different continents in 1996 and in 2016. EU has re-

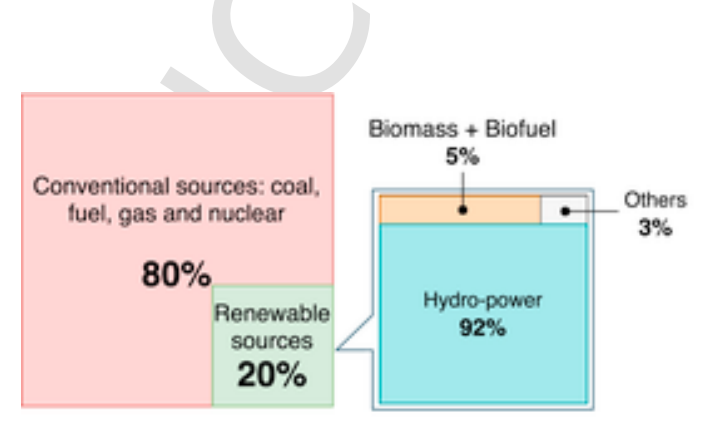

(a) Generation mix in 1996

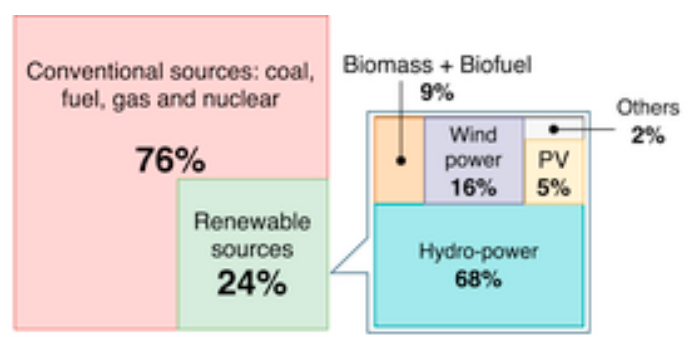

(b) Generation mix in 2016

Fig. 4. Generation mix in the world: change between 1996 and 2016. 


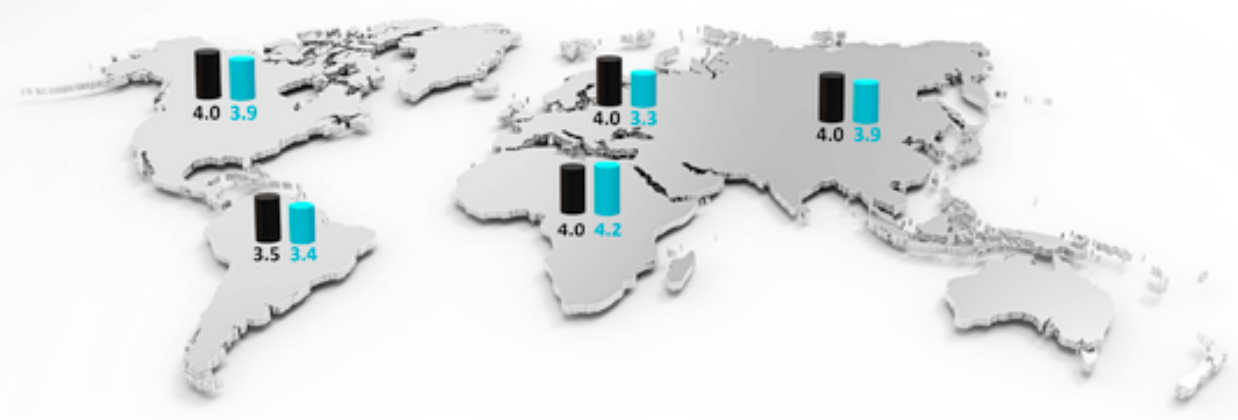

Fig. 5. Equivalent inertia constants estimated in the world by continent. Change between 1996 and 2016.

duced the equivalent inertia constant by nearly $20 \%$. In contrast, the reduction of inertia in Asia, USA, and South America lies between 2.5 and $3 \%$.

A more extensive analysis is conducted for the EU, where an average inertia reduction of $0.6 \mathrm{~s}$ can be estimated. In Fig. 6, an overview of the evolution of the equivalent inertia in some EU countries is summarized. Similar information is given in Fig. 7, where the reduction

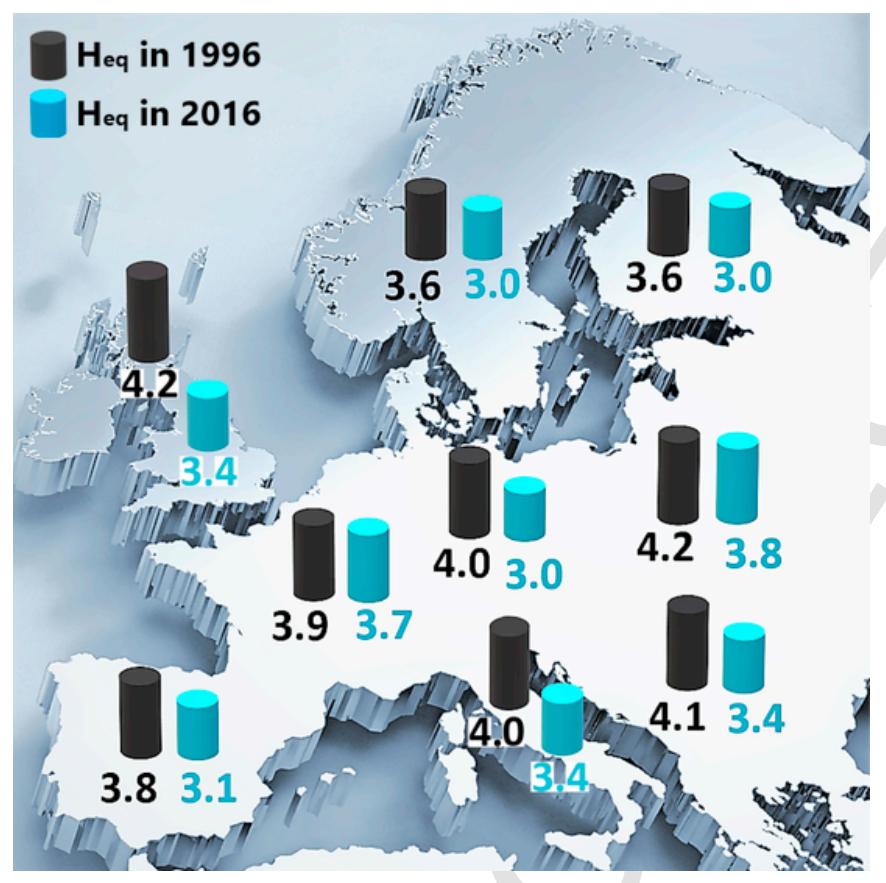

Fig. 6. Equivalent inertia constants estimated in EU-28. Change between 1996 and 2016.

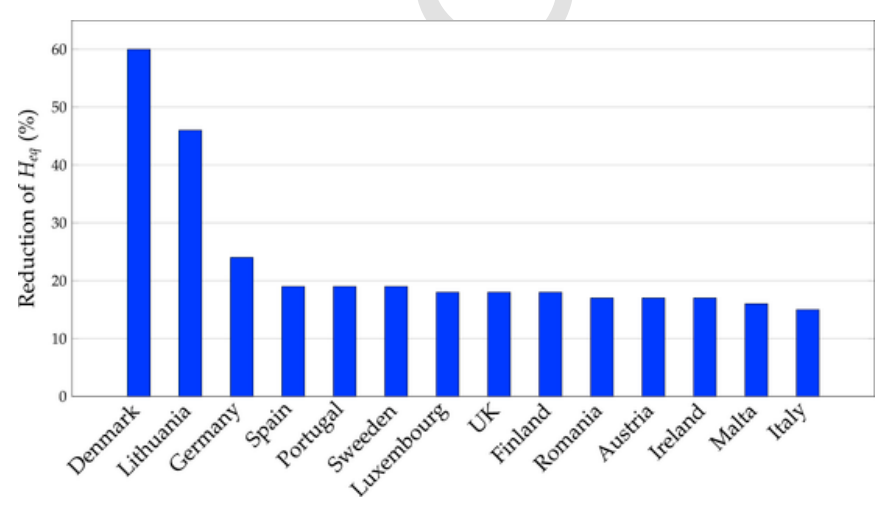

Fig. 7. Equivalent inertia reduction in EU-28 between 1996 and 2016. of the equivalent inertia is illustrated for those EU countries which have suffered a reduction larger than $15 \%\left(H_{e q}\right.$ reduction $\left.>15 \%\right)$. Fig. 8 represents the equivalent inertia evolution of $\mathrm{EU}$, as well as in three different countries (Ireland, Spain, and Denmark). For the EU, RES supply has increased nearly by $20 \%$, in line with the reduction of its inertia constant (refer to Fig. 9). Similar to the generation mix in the world, wind, biomass, biofuels, and PV have surpassed the development of hydro-power, which has drastically slowed down in recent years.

\subsection{Modified equivalent inertia analysis: emulating hidden and virtual inertia from RES}

To obtain the maximum power from the natural resource, both wind and PV power plants are controlled by power converters using the maximum power point tracking (MPPT) technique [48]. This power converter prevents wind and PV power plants to directly contribute to the inertia of the system, being thus referred to as 'decoupled' from the grid [49]. As a consequence, to effectively integrate RES into the grid, frequency control strategies have been developed [50-52]. Such methods are commonly named as synthetic, emulated or virtual inertia [53]. If this emulation of inertia coming from RES was included in power systems, it would have to be considered to estimate the equivalent inertia. Then, this modified equivalent inertia would have two different components: (i) synchronous inertia coming from conventional generators, $H_{S}$ and (ii) emulated/virtual inertia coming from RES, $H_{E V}$ [34,54-57], modifying Eq. (7) to Eq. (9). EVG is the number of

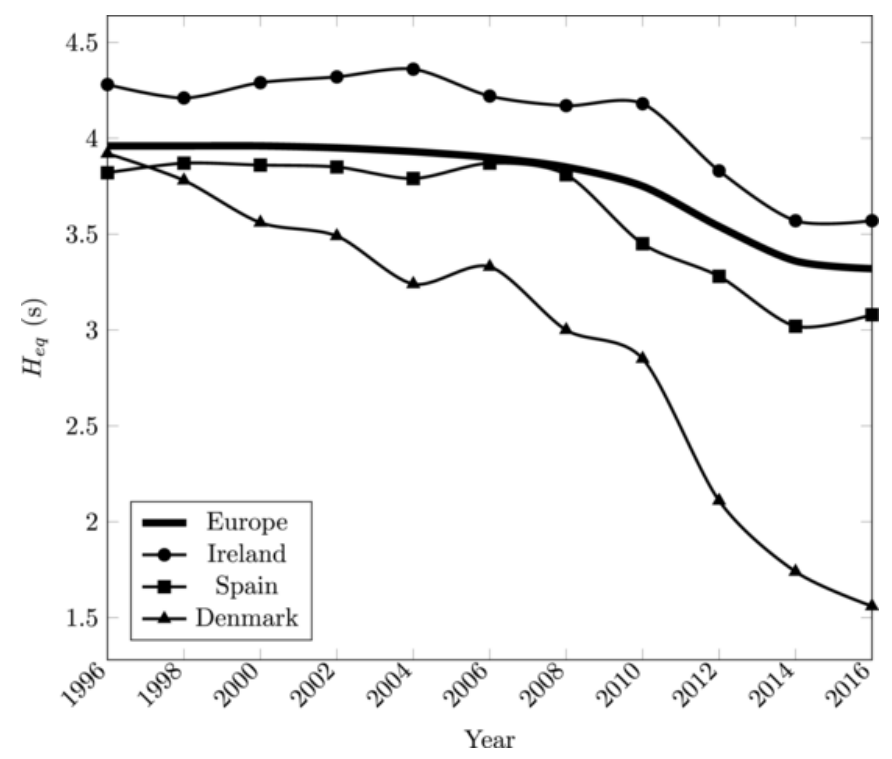

Fig. 8. Evolution of equivalent inertia in EU-28 and some countries between 1996 and 2016. 


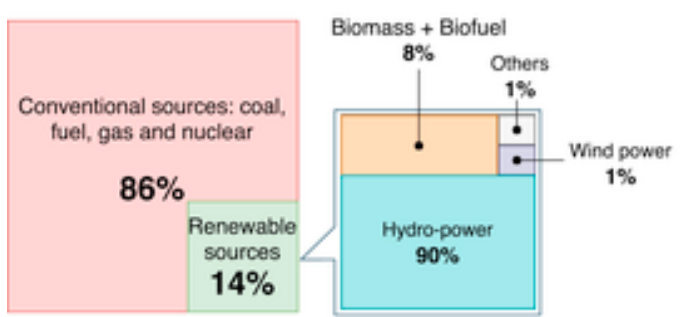

(a) Generation mix in 1996

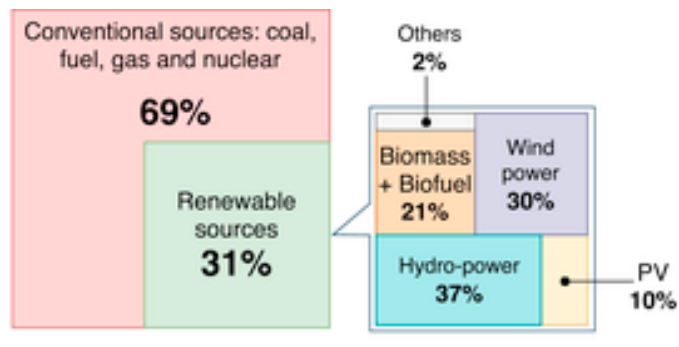

(b) Generation mix in 2016

Fig. 9. Generation mix in Europe: change between 1996 and 2016.

RES connected to the grid through emulation/virtual control methods, and $H_{E V}$ is the inertia constant of the emulated/virtual generation unit.

$$
H_{e q}=\frac{\overbrace{\sum_{i=1}^{G C P S} H_{i} \cdot S_{\text {base }, i}}^{H_{S}}+\overbrace{\sum_{j=1}^{E V G} H_{E V, j} \cdot S_{\text {base }, j}}^{H_{E V}} .}{S_{\text {base }}} .
$$

This modified equivalent inertia expressed in Eq. (9) is graphically illustrated in Fig. 10, based on [58]. Note the different representation between the coupling of VSWT and PV to the grid. The reason to this is that WPP has 'hidden' deployable inertia based on the kinetic energy stored in their blades, drive train and electrical generators, whereas PV has no stored kinetic energy due to the absence of rotating masses. Actually, modern VSWT have rotational inertia constants comparable to those of conventional generators $[30,59,60]$. However, this inertia is 'hidden' from the power system point of view due to the converter [61]. For instance, in Table 3 and Fig. 11, the inertia constant of several types of wind turbines are summarized, and most of them are within the range $2-6 \mathrm{~s}$, in line with values presented for conventional units in Table 1 . As a consequence, it is commonly considered that VSWT provide 'emulated hidden inertia', as rotational inertia could be provided by them [62-65]. On the other hand, PV installations don't have any rotating masses $[11,66]$, having an inertia constant $H \approx 0$ [67]. Therefore, due to this absence of rotational masses and, subsequently, absence of inertia, the specific literature refers to the "emu-

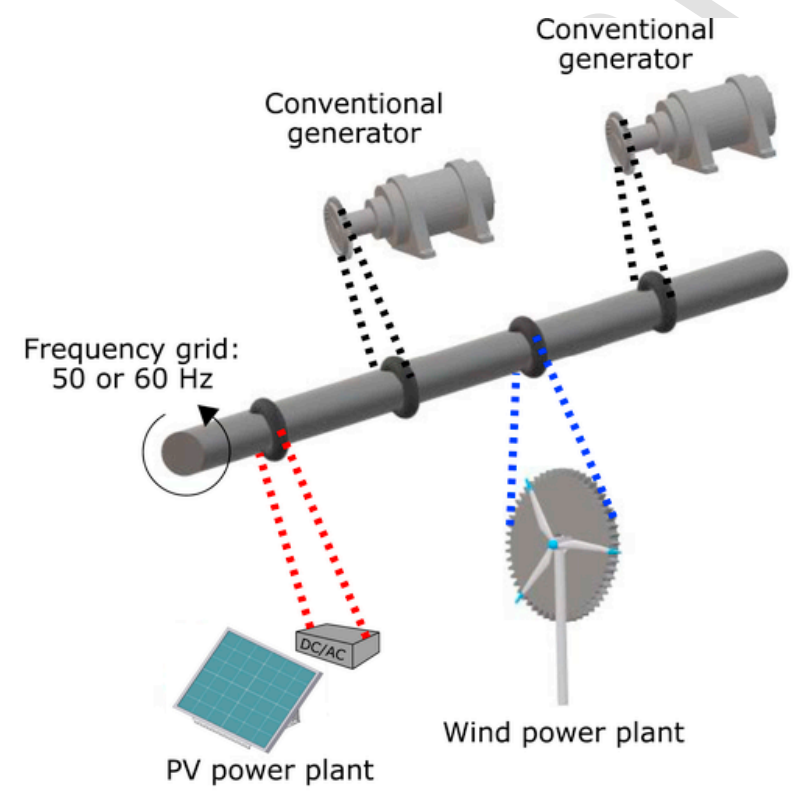

Table 3

Wind turbines inertia constants $H$ according to rated power and reference.

\begin{tabular}{|c|c|c|c|c|}
\hline Type of wind turbine & Rated power & $H(\mathrm{~s})$ & Reference & Year \\
\hline Not indicated & Not indicated & $2-5$ & [12] & 2012 \\
\hline Not indicated & $2 \mathrm{MW}$ & 4.45 & [72] & 2007 \\
\hline Not indicated & $2 \mathrm{MW}$ & 2.5 & [73] & 2003 \\
\hline Not indicated & $16 \cdot 600 \mathrm{~kW}$ & 3.7 & [74] & 2003 \\
\hline HAWT with SCIG & $200 \mathrm{~kW}$ & 1.2 & [75] & 2010 \\
\hline FSWT & $10 \cdot 500 \mathrm{~kW}$ & 3.2 & [76] & 2005 \\
\hline FSWT & Not indicated & 3.5 & [77] & 2005 \\
\hline VSWT & $2 \mathrm{MW}$ & 6 & [78] & 2006 \\
\hline VSWT & $3.6 \mathrm{MW}$ & 5.19 & [79] & 2008 \\
\hline Types $1,2,3$ & $1-5 \mathrm{MW}$ & $2.4-6.8$ & {$[80]$} & 2005 \\
\hline DFIG & $2 \mathrm{MW}$ & 3.5 & [81] & 2003 \\
\hline DFIG & $660 \mathrm{~kW}$ & 4 & {$[82]$} & 2006 \\
\hline DFIG & $1.5 \mathrm{MW}$ & 6.35 & [83] & 2009 \\
\hline DFIG & $1.5 \mathrm{MW}$ & 4.41 & [83] & 2009 \\
\hline DFIG & $3.6 \mathrm{MW}$ & 4.29 & [84] & 2011 \\
\hline DFIG & $2 \mathrm{MW}$ & 3.5 & [85] & 2003 \\
\hline DFIG & $2 \mathrm{MW}$ & 2.5 & [86] & 2004 \\
\hline DFIG & $660 \mathrm{~kW}$ & 4 & [24] & 2007 \\
\hline DFIG (WPP) & $300 \mathrm{MW}$ & 1 & [87] & 2007 \\
\hline DFIG & $750 \mathrm{MW}$ & 5.4 & [88] & 2005 \\
\hline DFIG & $2 \mathrm{MW}$ & 3 & [89] & 2013 \\
\hline DFIG & $1.5 \mathrm{MW}$ & 3 & [90] & 2012 \\
\hline DFIG & $2 \mathrm{MW}$ & 0.5 & [91] & 2006 \\
\hline DFIG & $2 \mathrm{MW}$ & 3.5 & [92] & 2003 \\
\hline PMSG & $455 \mathrm{~kW}$ & 2.833 & [93] & 1996 \\
\hline
\end{tabular}

lated synthetic/virtual inertia' provided by such PV power plants [68-71].

With regard to the equivalent inertia estimation for the EU, and considering the averaged hidden inertia of WPP depicted in Table 3, the inertia change is reduced around $0.3 \mathrm{~s}$, corresponding to $50 \%$ of the value determined in Section 2.2. Fig. 12 presents the evolution of the equivalent inertia in the same EU countries of Fig. 6, being the dark blue values those due to the hidden inertia provided by VSWTs. As can be seen, by considering the hidden inertia of VSWT leads to a smaller reduction of the equivalent inertia.

\section{RES frequency control strategies}

\subsection{Preliminaries}

Generation and load in the power systems must be continuously balanced to maintain a steady frequency. Under any generation-load mismatch, grid frequency changes [94]. Moreover, significant deviations from the nominal value may cause under/over frequency relay operations, and even lead to the disconnection of some loads from the grid [95]. Consequently, frequency stability is related to the ability of

Fig. 10. Power system with synchronous, hidden and virtual inertia. 


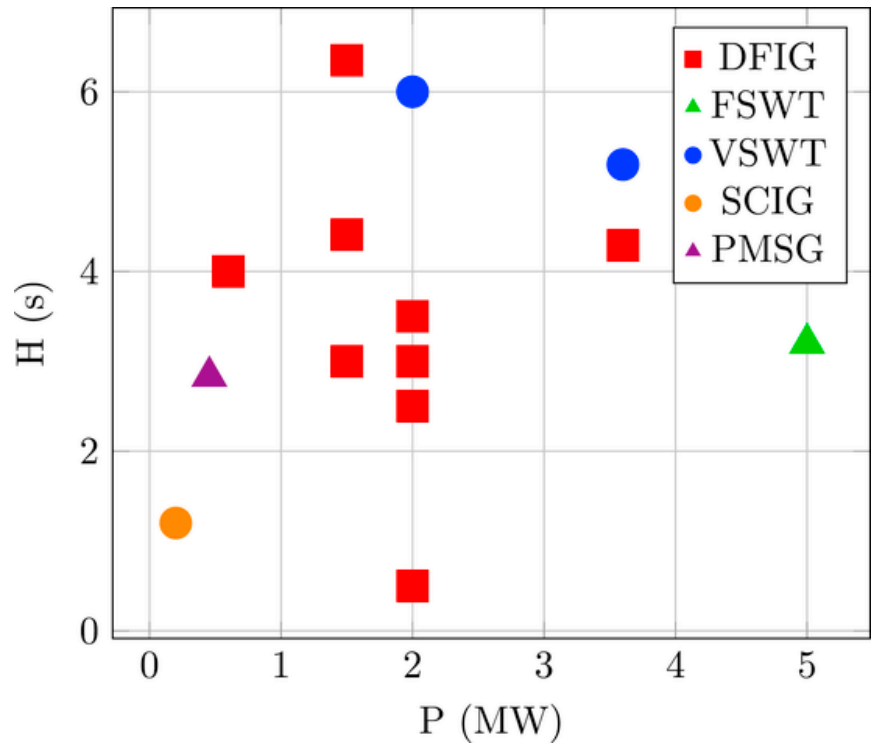

Fig. 11. Inertia constant values $(H)$ for different wind turbine technologies.

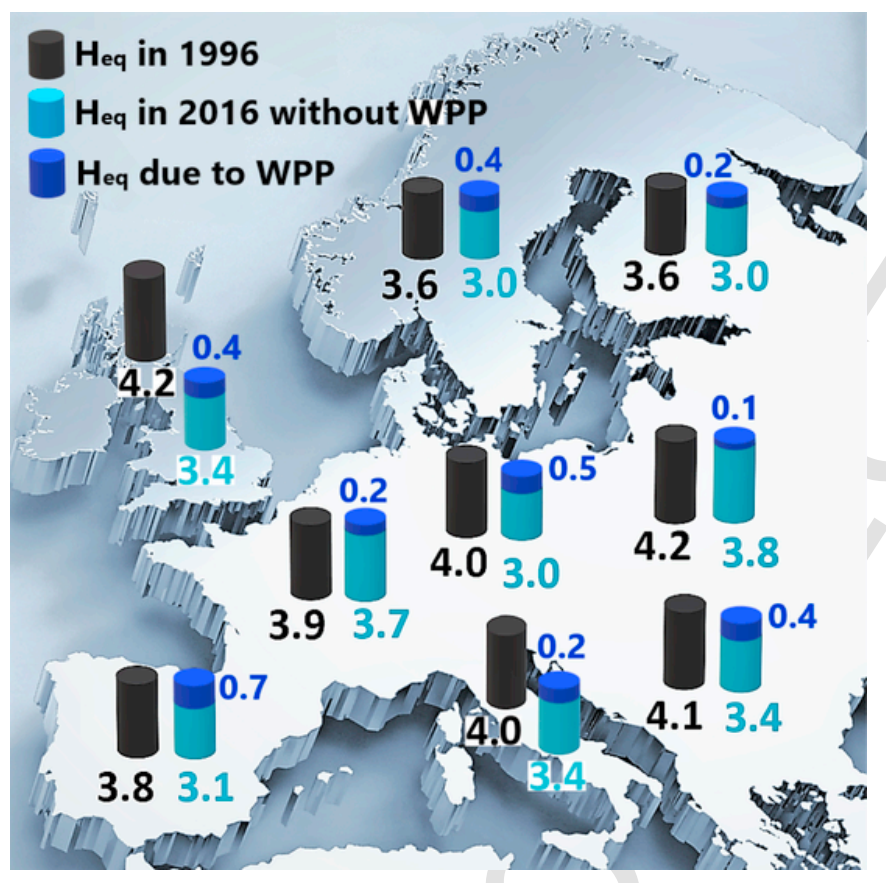

Fig. 12. Equivalent averaged inertia constants estimated in EU-28 considering emulated inertia provided by WPPs (1996-2016).

a power system to maintain the operating frequency close to its nominal value (i.e., 50 or $60 \mathrm{~Hz}$, depending on the region) when an imbalance situation occurs [96]. Hence, frequency control is an essential component of a secure and robust electrical power system [97].

Frequency control is traditionally implemented by adjusting real power generation to balance the load. This traditional scheme has a hierarchical structure, and in Europe it is usually composed of three layers: primary, secondary and tertiary, from fast to slow timescales [98]. The primary and secondary controls are automatic, while tertiary control is manually executed by the transmission system operator [99].

The primary frequency control (PFC) operates at a timescale up to low tens of seconds and uses a governor to adjust the mechanical power input around a set-point based on the local frequency deviation [100]. It is the automatic response of the turbine governors in response to the deviations of the system frequency and depends on the setting of the speed-droop characteristics of each power plant [101]. Therefore, each generating unit can be modeled with its speed governing system [102]. However, it does not restore grid frequency to its nominal value [103]. In Europe, primary control is triggered before the frequency deviation exceeds $\pm 20 \mathrm{mHz}$ [104].

Secondary frequency control or automatic generation control (AGC) removes the steady-state frequency deviation generated by the PFC [105]. An integral controller modifies the turbine governor set-point to bring the frequency back to its nominal value [106]. It also keeps the scheduled exchanges between the different areas of an interconnected power system to their expected values [107]. In Europe, the time-frame is from seconds up to typically $15 \mathrm{~min}$ after an incident [104]. Fig. 13 gives an example of a typical frequency excursion, where primary frequency control and AGC time intervals are shown.

Finally, the main objective of the tertiary frequency control is to perform an economically efficient generation-dispatch (economic dispatch) [108]. Moreover, it is also intended to relieve transmission congestions and restoring the secondary control reserves [109]. This is also called security-constrained-economic dispatch (SCED).

An increase in the penetration level of RES addresses a decreasing of the number of synchronous generators, leading to an initial decline in system inertia and power reserves for primary and secondary control [110]. Subsequently, low inertia is related to larger frequency deviations after a generation-load mismatch event [111], having implications on frequency related power systems dynamics [112]. It is important to note that the rate of change of frequency (ROCOF) is strongly affected by the inertia available in the system [113]. By this means, it is necessary that RES become an active role in grid frequency regulation, providing active power support under disturbances [114]. The different technologies proposed to give additional inertia and frequency control from RES are usually classified as summarized in Fig. 14.

\section{2. $P V$ power plant frequency control strategies}

PV power plants can use ESS such as batteries [115-117], super-capacitors [118,119] and flywheels [117] in order to provide additional active power in an imbalanced situation.

A different strategy to be considered is the 'de-loading technique' of the PV plant. It is based on operating these generating units below their optimal generation point, in order to have a certain amount (headroom) of active power to supply real power to the grid in case of a frequency-dip contingency [120]. In general, PV power plants operate at the maximum power point tracking mode according to certain meteorological conditions (i.e., temperature $T$ and irradiation $G$ ), maximizing the revenues from selling energy [121]. Contributions focused on this technique can be found in Refs. [122-127]. By curtailment, we are operating the PV plant at a de-loaded point $P_{d e l}$, below $P_{M P P}$, so that the PV plants are able to support system frequency, as some power reserves $\Delta P=P_{M P P}-P_{d e l}$ are available. As depicted in Fig. $15, P_{d e l}$ involves two different voltages: $(i)$ over the maximum power point voltage, $V_{d e l, 1}>V_{M P P}$ and (ii) under the maximum power point volt-

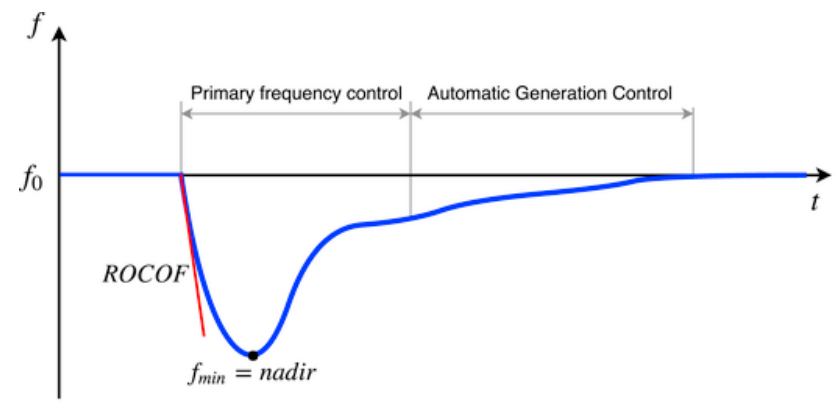

Fig. 13. Frequency response after an imbalance. 


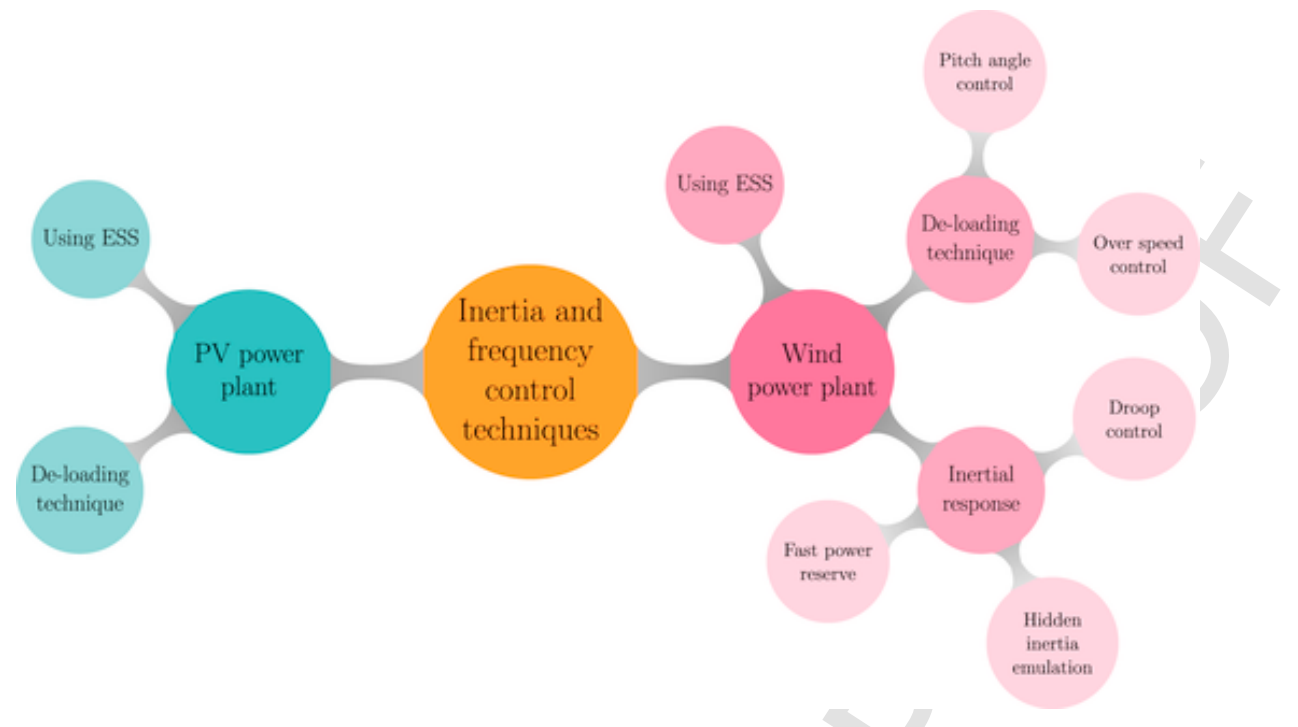

Fig. 14. Inertia and frequency control techniques for RES.

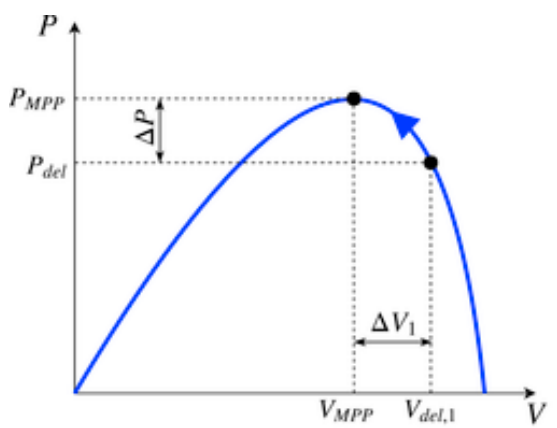

(a) $V_{\text {del, } 1}>V_{M P P}$

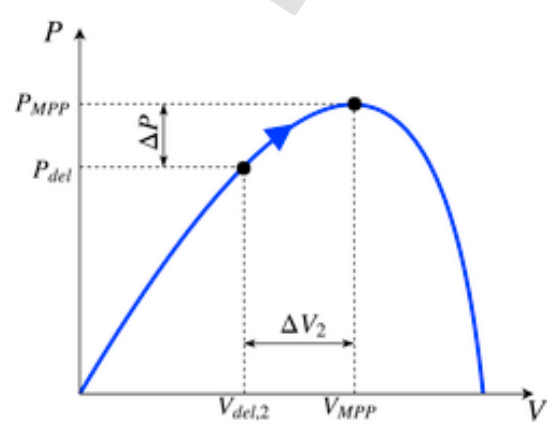

(b) $V_{d e l, 2}<V_{M P P}$

Fig. 15. Deloading techniques for PV.

age, $V_{d e l, 2}<V_{M P P}$. Due to stability concerns, the de-loaded voltage corresponds to the higher value $V_{d e l, 1}[128]$.

\subsection{Wind power plant frequency control strategies}

As in the PV power plants, wind power plants can also use ESS to provide additional power boost during an imbalanced situation (i.e., frequency dips). Batteries [116], super-capacitors [118,129] and flywheels [130] are proposed in the literature review.

Wind turbines have two possibilities to operate with the de-loading technique: (i) pitch angle control and (ii) over-speed control [61]. The pitch angle control consists of increasing the pitch angle from $\beta_{0}$ to $\beta_{1}$ for a constant wind speed $V_{W}$, keeping the rotor speed at the maximum power point $\Omega_{M P P}$ (Fig. 16). This way, the power supplied $P_{d e l}$ is below the maximum available aerodynamic power $P_{M P P}$. Therefore, a certain amount of active power reserve is available to supply additional generation in case of a frequency deviation occurs [131-134]. The over-speed control shifts the de-loaded power $P_{d e l}$ towards the right of the maximum power $P_{M P P}$, maintaining the pitch angle $\beta_{0}$ for a constant wind speed $V_{W}$, see Fig. 17(a). When frequency response is provided, rotor speed has to be reduced from $\Omega_{d e l, 1}$ to $\Omega_{M P P}$, releasing kinetic energy to the system [135-138]. As depicted in Fig. 17(b), a third possibility could be to set the turbine to operate the rotor speed below the rotor speed for MPPT operation. In that case, the rotor speed must increase from $\Omega_{d e l, 2}$ to $\Omega_{M P P}$ utilizing some power extracted from the turbine. As a consequence, the frequency response is reduced,

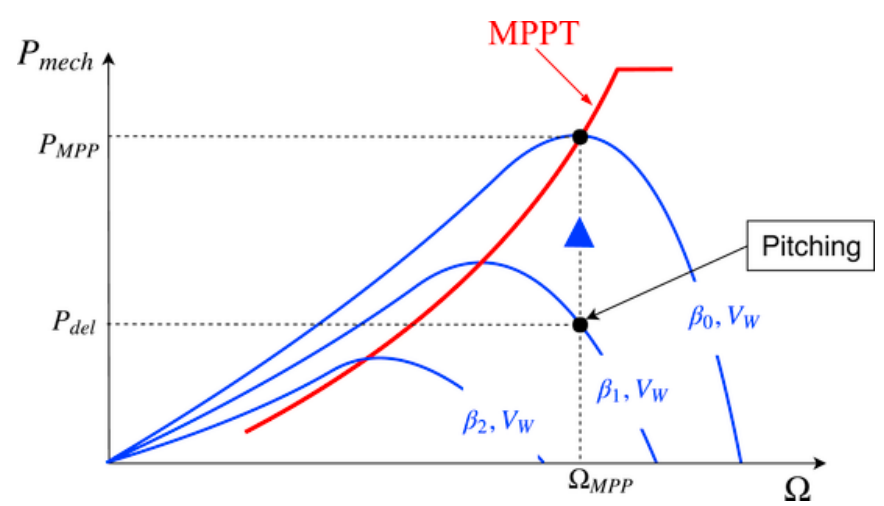

Fig. 16. Pitch control.

and could even be opposite to the desired behavior during the first seconds. Because of this, it is usually considered as a 'detrimental strategy' [139,140].

With regard to providing an inertial response from wind power plants, the main idea is to increase the output power of the VSWT for a few seconds. One or more supplementary loops are introduced into the active power control, which are only activated under frequency deviations. Both blades and rotor inertia are then used to provide primary frequency response under power imbalance situations. The kinetic energy stored in the rotating masses is supplied to the grid as an additional active power [141]. 


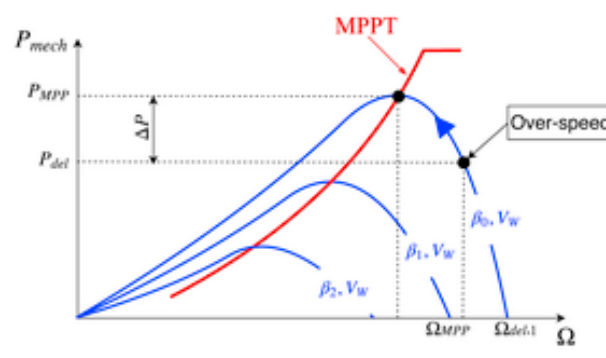

(a) Over-speed control

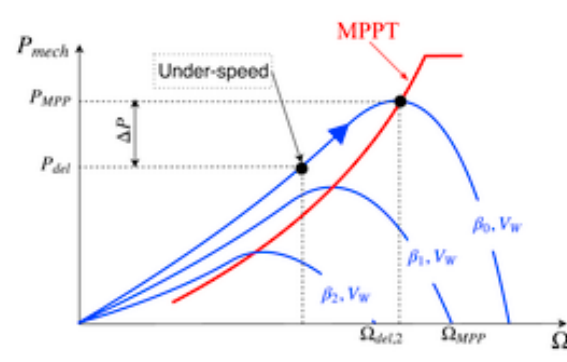

(b) Under-speed control

Fig. 17. Over-speed and under-speed control.

The droop control emulates the behavior of a governor in a conventional synchronous generator, responding to the changes in the system frequency. The active power supplied by the VSWTs changes proportionally to the frequency deviation $\Delta f$ as illustrated in Fig. 18(a), where $R_{W T}$ is the droop control setting (speed adjustment rate). Subsequently, the variation of power is defined as Eq. (10), where $\Delta P$ is the signal given to the power converter to release the stored kinetic energy. The increase of the active power output results in a decrease in the rotor speed [142-145[146]].

$\Delta P=-\frac{\Delta f}{R_{W T}}$

Hidden inertia emulation for wind turbines is characterized by an emulation of the inertial response of a traditional synchronous generator. There are two types of hidden inertia emulation controls: (i) one loop and (ii) two loops. In the first case, an additional power $\Delta P$ based on the ROCOF is added to $P_{M P P}$ after a generation deficit, thus, reducing the generator speed and releasing the stored kinetic energy of the rotating blades [147-149]. The drawback of this control strategy is that frequency is not restored to its nominal value [150]. An additional loop proportional to the frequency deviation $\Delta f$ is then added, as indicated in Fig. 19(b). This second loop lasts until the frequency is restored to $f_{0}[78,151]$. Fig. 20 compares the frequency responses by considering one or two loops controllers.
The fast power reserve technique is based on supplying the kinetic energy stored in the rotating masses of the wind turbine to the grid as additional active power. Afterward, the energy extracted is recovered through an under-production period. When the frequency deviation surpasses the predefined threshold value, the additional active power is provided, decreasing the rotational speed of the rotor. Overproduction power was initially defined as a constant value [79,152-156]. However, new approaches consider it as variable [157-159] by considering other limits (e.g. toque limit, the current limit of the power electronic switches, etc). The recovery period is used to restore both power and rotational speed to their pre-event values. Different techniques have also been proposed in the references listed. Fig. 21 shows the fast power reserve emulation control indicated in Ref. [152].

Table 4 presents an overview of the application of some of the techniques. It includes the integration of wind power plants (WPP) and the power imbalance $\Delta P$; both in the percentage of the total capacity of the system. As can be seen, some strategies are combined, in order to improve the frequency deviation after the generation-load mismatch.

\section{Conclusion}

An extensive literature review focused on inertia estimation for power systems and wind power plants is conducted by the authors. The contribution of PV power plants as a 'virtual inertia' is also discussed in the paper, as well as a detailed analysis of the damping factor evolu-

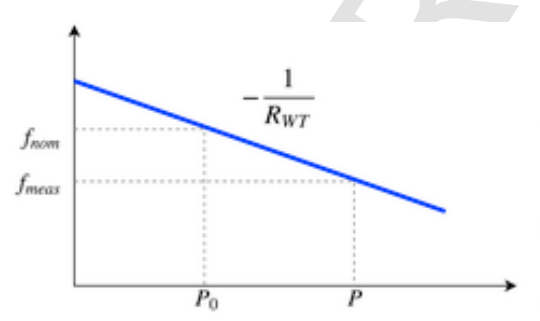

(a) Droop characteristic

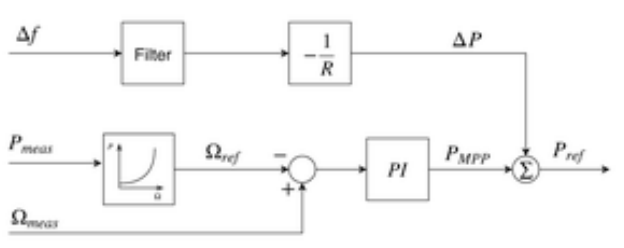

(b) Block diagram of droop control [146]

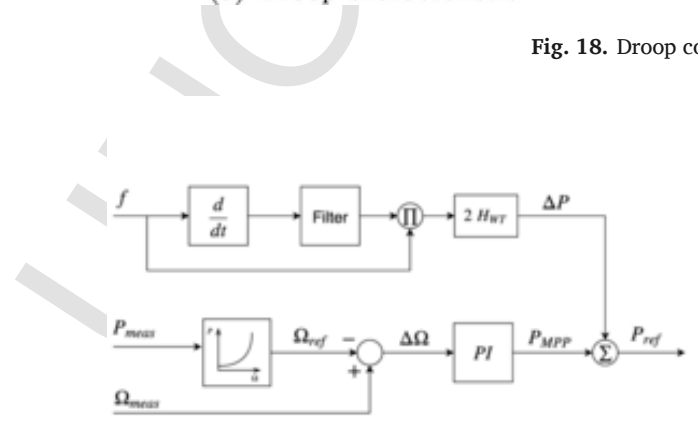

(a) One loop

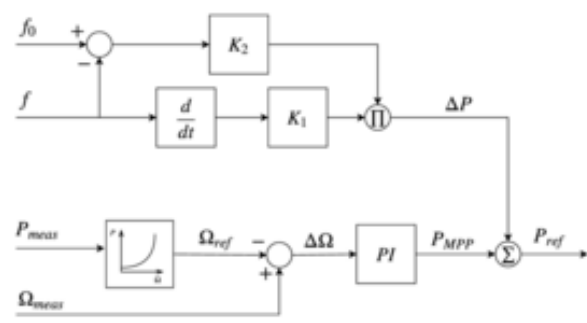

(b) Two loops

Fig. 19. Hidden inertia emulation controllers. 


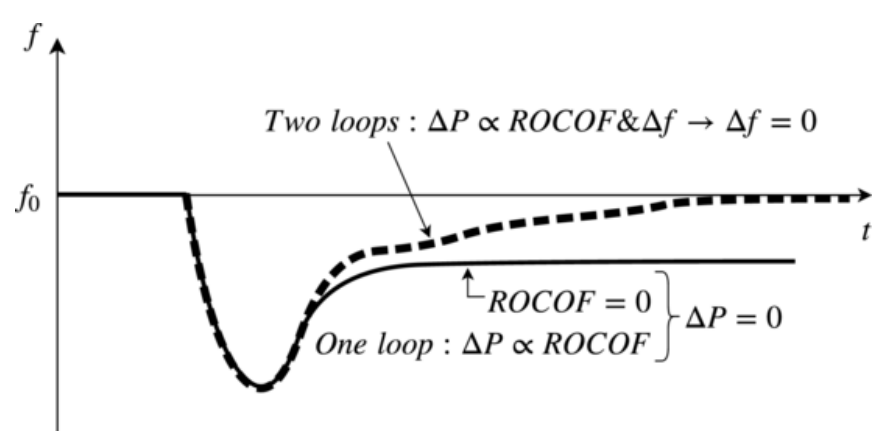

Fig. 20. Frequency response of the one loop and two loops controllers.

tion. Averaged inertia values are estimated for different regions and countries for the last two decades. Conventional generation units are considered accordingly, summarizing their inertia constant values in accordance with each type of technology and rated power. Our findings indicate that, nowadays, Europe presents a significant averaged inertia decreasing -around $20 \%$ in the last two decades-, mainly due to the renewable integration decoupled from the grid -from 14\% in 1996 to $31 \%$ in $2016-$. With regard to wind turbines, they present inertia values similar to conventional generation units -between 2 and $6 \mathrm{~s}$ depending on technologies-, which is commonly considered as 'emulated hidden inertia'. The paper provides significant information for wind turbines frequency control strategies and studies of current power systems with high renewable energy source integration.

\section{Funding}

This work was supported by the Spanish Education, Culture and Sports Ministry [FPU16/04282].

[] .

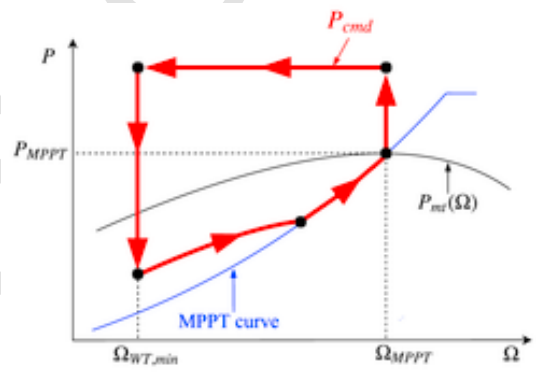

(a) $P-\Omega$ curve

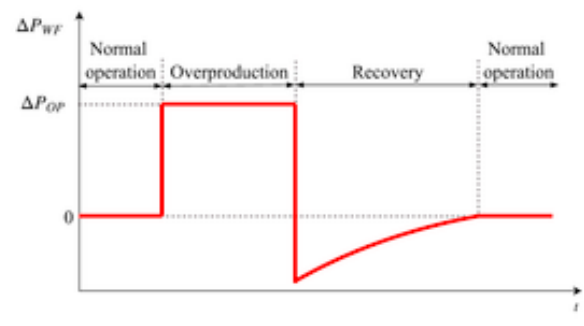

(b) Power variation

Fig. 21. Fast power reserve emulation technique [152]. 
Table 4

Wind turbines frequency control proposals.

\begin{tabular}{lllll}
\hline & & WPP & & \\
Ref. & Type of control & $(\%)$ & $\Delta P(\%)$ & Year \\
\hline$[160]$ & Droop & 46 & 14 & 2012 \\
{$[160]$} & Hidden inertia $(i)$ & 46 & 14 & 2012 \\
{$[160]$} & Droop + Hidden inertia $(i)$ & 46 & 14 & 2012 \\
{$[161]$} & Variable droop & 30 & - & 2011 \\
{$[162]$} & De-loading by pitch & 24 & 3 & 2016 \\
{$[162]$} & De-loading by pitch & 50 & 4 & 2016 \\
{$[163]$} & Fast power reserve & 57 & 8.5 & 2017 \\
{$[164]$} & Hidden inertia $(i i)$ & 25 & 1.7 & 2012 \\
{$[165]$} & Dynamic droop + Hidden inertia $(i)$ & 10 & $8.5,10$, & 2016 \\
& & & 11 & \\
{$[166]$} & Droop + Hidden inertia $(i)$ & 15 & 2 & 2016 \\
{$[166]$} & Droop + Hidden inertia $(i)$ & 50 & 2 & 2016 \\
{$[167]$} & Fast power reserve & 12.5 & 6.25 & 2015 \\
{$[168]$} & Hidden inertia $(i)$ & 20 & 8.33 & 2015 \\
{$[168]$} & Droop & 20 & 8.33 & 2015 \\
{$[168]$} & Droop & 20 & 8.33 & 2015 \\
{$[169]$} & Hidden inertia $(i i)$ & 30 & 2.5 & 2013 \\
{$[170]$} & Hidden inertia $(i)$ & 38 & 2.3 & 2012 \\
{$[170]$} & De-loading by pitch + Over-speed & 38 & 2.3 & 2012 \\
{$[170]$} & Hidden inertia $(i)+$ Pitch + Over- & 38 & 2.3 & 2012 \\
& speed & & &
\end{tabular}

\section{References}

[1] R D'hulst, JM Fernandez, E Rikos, D Kolodziej, K Heussen, D Geibelk, et al. Voltag and frequency control for future power systems: the ELECTRA IRP proposal. Smart electric distribution systems and technologies (EDST), 2015 International symposium on. IEEE; 2015. p. 245-250.

[2] I Hadjipaschalis, A Poullikkas, V Efthimiou. Overview of current and future energy storage technologies for electric power applications. Renew Sustain Energy Rev 2009;13(6-7):1513-1522.

[3] H Bevrani, A Ghosh, G Ledwich. Renewable energy sources and frequency regulation: survey and new perspectives. IET Renew Power Gener 2010;4(5):438-457.

[4] Tech. rep.. The European power sector in 2017. State of affairs and review of current developments. Agora Energiewende and Sandbag; Jan. 2018.

[5] B Zakeri, S Syri, S Rinne. Higher renewable energy integration into the existing energy system of Finland-is there any maximum limit? Energy 2015;92:244-259.

[6] S Weitemeyer, D Kleinhans, T Vogt, C Agert. Integration of Renewable Energy Sources in future power systems: the role of storage. Renew Energy 2015;75:14-20.

[7] D Groß, F Dörfler. On the steady-state behavior of low-inertia power systems. IFAC-PapersOnLine 2017;50(1):10735-10741.

[8] Technology roadmap: solar photovoltaic energy. International Energy Agency; 2014.

[9] Wind energy in Europe: scenarios for 2030. Wind Europe; 2017.

[10] D Ochoa, S Martinez. Fast-frequency response provided by DFIG-wind turbines and its impact on the grid. IEEE Trans Power Syst 2017;32(5):4002-4011. doi:10.1109/ TPWRS.2016.2636374

[11] R Shah, N Mithulananthan, R Bansal, V Ramachandaramurthy. A review of key power system stability challenges for large-scale PV integration. Renew Sustain Energy Rev 2015;41(Supplement C):1423-1436. https://doi.org/10.1016/j.rser.2014. 09.027 .

[12] P. Tielens D. Van Hertem Grid inertia and frequency control in power systems with high penetration of renewables $\Omega$ [freely_available]https://lirias.kuleuven.be/ retrieve/182648\$\$DGrid_Inertia_and_Frequency_Control_in_Power_Systems_with_ High_Penetration_of_Renewables.pdf2012

[13] TH Mohamed, J Morel, H Bevrani, T Hiyama. Model predictive based load frequency control_design concerning wind turbines. Int J Electr Power Energy Syst 2012;43(1):859-867.

[14] I Erlich, M Wilch. Primary frequency control by wind turbines. Power and energy society general meeting, 2010 IEEE. IEEE; 2010. p. 1-8.

[15] D Gautam, L Goel, R Ayyanar, V Vittal, T Harbour. Control strategy to mitigate the impact of reduced inertia due to doubly fed induction generators on large power systems. IEEE Trans Power Syst 2011;26(1):214-224.

[16] N Nguyen, J Mitra. Reliability of power system with high wind penetration under frequency stability constraint. IEEE Trans Power Syst 2018;33(1):985-994.

[17] P Du, J Matevosyan. Forecast system inertia condition and its impact to integrate more renewables. IEEE Trans on Smart Grid 2018;9(2):1531-1533.

[18] G Delille, B Francois, G Malarange. Dynamic frequency control support by energy storage to reduce the impact of wind and solar generation on isolated power system's inertia. IEEE Trans Sustain Energy 2012;3(4):931-939.
[19] P Daly, D Flynn, N Cunniffe. Inertia considerations within unit commitment and economic dispatch for systems with high non-synchronous penetrations. PowerTech, 2015 IEEE eindhoven. IEEE; 2015. p. 1-6.

[20] I Boldea. Synchronous generators. CRC Press; 2015

[21] A Fernández-Guillamón, A Vigueras-Rodríguez, A Molina-García. Análisis y simulación de estrategias agregadas de control de frecuencia entre grandes parques eólicos y aprovechamientos hidroeléctricos M.S. thesis. Universidad Politécnica de Cartagena; 2017.

[22] PM Anderson, AA Fouad. Power system control and stability. John Wiley \& Sons; 2008.

[23] P Dabur, NK Yadav, VK Tayal. Matlab design and simulation of AGC and AVR for multi-area power system and demand-side management. Int J Comput Electr Eng 2011;3(2):259.

[24] RG De Almeida, JP Lopes. Participation of doubly fed induction wind generators in system frequency regulation. IEEE Trans Power Syst 2007;22(3):944-950.

[25] S Kumal, et al. Agc and avr of interconnected thermal power system while considering the effect of grc's. Int J Soft Comput Eng 2012;2.

[26] P Kundur, NJ Balu, MG Lauby. Power system stability and control, 7. New York: McGraw-hill; 1994.

[27] UNED. Centrales eléctricas. el alternador; 2011.

[28] M Shahidehpour, M Eremia, L Toma. Modeling the main components of the classical power plants. Handbook of electrical power system dynamics: modeling, stability, and control; 2013. p. 137-178.

[29] JJ Grainger, WD Stevenson. Power system analysis. McGraw-Hill; 1994.

[30] E Spahic, D Varma, G Beck, G Kuhn, V Hild. Impact of reduced system inertia on stable power system operation and an overview of possible solutions. Power and energy society general meeting (PESGM), 2016. IEEE; 2016. p. 1-5.

[31] E Chiodo, D Lauria, F Mottola. On-line Bayes estimation of rotational inertia for power systems with high penetration of renewables. part i: theoretical methodology. 2018 International symposium on power electronics, electrical drives, automation and motion (SPEEDAM). IEEE; 2018. p. 835-840.

[32] A Ulbig, TS Borsche, G Andersson. Impact of low rotational inertia on power system stability and operation. IFAC Proc Vol 2014;47(3):7290-7297.

[33] H Huang, F Li. Sensitivity analysis of load-damping characteristic in power system frequency regulation. IEEE Trans Power Syst 2013;28(2):1324-1335.

[34] P Tielens, D Van Hertem. The relevance of inertia in power systems. Renew Sustain Energy Rev 2016;55:999-1009.

[35] E Ali, S Abd-Elazim. Bacteria foraging optimization algorithm based load frequency controller for interconnected power system. Int J Electr Power Energy Syst 2011;33(3):633-638.

[36] K Sudha, RV Santhi. Robust decentralized load frequency control of interconnected power system with generation rate constraint using type-2 fuzzy approach. Int $\mathrm{J}$ Electr Power Energy Syst 2011;33(3):699-707.

[37] L Jiang, W Yao, Q Wu, J Wen, S Cheng, et al. Delay-dependent stability for load frequency control with constant and time-varying delays. IEEE Trans Power Syst 2012;27(2):932.

[38] T Masuta, A Yokoyama. Supplementary load frequency control by use of a number of both electric vehicles and heat pump water heaters. IEEE Trans Smart Grid 2012;3(3):1253-1262.

[39] H Shabani, B Vahidi, M Ebrahimpour. A robust pid controller based on imperialist competitive algorithm for load-frequency control of power systems. ISA Trans 2013;52(1):88-95.

[40] UK Rout, RK Sahu, S Panda. Design and analysis of differential evolution algorithm based automatic generation control for interconnected power system. Ain Shams Eng J 2013;4(3):409-421.

[41] RK Sahu, S Panda, UK Rout. De optimized parallel 2-dof pid controller for load frequency control of power system with governor dead-band nonlinearity. Int J Electr Power Energy Syst 2013;49:19-33.

[42] M Sathya, MMT Ansari. Load frequency control using bat inspired algorithm based dual mode gain scheduling of pi controllers for interconnected power system. Int $J$ Electr Power Energy Syst 2015;64:365-374.

[43] S Ruiz, J Patiño, J Espinosa, et al. Load frequency control of a multi-area power system incorporating variable-speed wind turbines. 2016.

[44] L Dong, Y Tang, H He, C Sun. An event-triggered approach for load frequency control with supplementary adp. IEEE Trans Power Syst 2017;32(1):581-589.

[45] C Peng, J Zhang, H Yan. Adaptive event-triggering $h_{\infty}$ load frequency control for network-based power systems. IEEE Trans Ind Electron 2018;65(2):1685-1694.

[46] Y Wu, Z Wei, J Weng, X Li, RH Deng. Resonance attacks on load frequency control of smart grids. IEEE Trans Smart Grid 2018;9(5):4490-4502.

[47] International Energy Agency Total primary energy supply (tpes) by source, year and countryhttps://www.iea.org/statistics/?country $=$ WORLD\&year $=2016 \&$ category $=$ Key $\% 20$ indicators\&indicator $=$ TPESbySource\&mode $=$ chart $\&$ categoryBrowse $=$ false $\&$ dataTable $=$ ELECTRICITYANDHEAT $\&$ showDataTable $=$ true17 October 2018

[48] S Muyeen, R Takahashi, T Murata, J Tamura. A variable speed wind turbine control strategy to meet wind farm grid code requirements. IEEE Trans Power Syst 2010;25(1):331-340.

[49] J Zhao, X Lyu, Y Fu, X Hu, F Li. Coordinated microgrid frequency regulation based on DFIG variable coefficient using virtual inertia and primary frequency control. IEEE Trans Energy Convers 2016;31(3):833-845.

[50] D Groß, S Bolognani, BK Poolla, F Dörfler. Increasing the resilience of low-inertia power systems by virtual inertia and damping. Bulk power systems dynamics and control symposium. IREP; 2017.

[51] T Kerdphol, F Rahman, Y Mitani, K Hongesombut, S Küfeoğlu. Virtual inertia control-based model predictive control for microgrid frequency stabilization considering high renewable energy integration. Sustainability 2017;9(5):773. 
[52] F Teng, Y Mu, H Jia, J Wu, P Zeng, G Strbac. Challenges on primary frequency control and potential solution from EVs in the future gb electricity system. Appl Energy 2017;194:353-362.

[53] I Vokony. Effect of inertia deficit on power system stability-synthetic inertia concepts analysis. Energy (IYCE), 2017 6th International youth conference on. IEEE; 2017. p. 1-6.

[54] J Morren. Grid support by power electronic converters of distributed generation units Ph.D. thesis. TU Delft; 2006.

[55] H Bevrani, T Ise, Y Miura. Virtual synchronous generators: a survey and new perspectives. Int J Electr Power Energy Syst 2014;54:244-254.

[56] H Gu, R Yan, TK Saha. Minimum synchronous inertia requirement of renewable power systems. IEEE Trans Power Syst 2017;33(2):1533-1543.

[57] P Tielens, D Van Hertem. Receding horizon control of wind power to provide frequency regulation. IEEE Trans Power Syst 2017;32(4):2663-2672.

[58] B Kroposki, B Johnson, Y Zhang, V Gevorgian, P Denholm, B-M Hodge, et al. Achieving a $100 \%$ renewable grid: operating electric power systems with extremely high levels of variable renewable energy. IEEE Power Energy Mag 2017;15(2):61-73.

[59] H Thiesen, C Jauch, A Gloe. Design of a system substituting today's inherent inertia in the European continental synchronous area. Energies 2016;9(8):582.

[60] DS Simonetti, AE Amorim, FD Oliveira. Doubly fed induction generator in wind energy conversion systems. Advances in renewable energies and power technologies. Elsevier; 2018. p. 461-490.

[61] X Yingcheng, T Nengling. Review of contribution to frequency control through variable speed wind turbine. Renew Energy 2011;36(6):1671-1677.

[62] L Ruttledge, D Flynn. Emulated inertial response from wind turbines: gain scheduling and resource coordination. IEEE Trans Power Syst 2015;31(5):3747-3755.

[63] J Van de Vyver, JD De Kooning, B Meersman, L Vandevelde, TL Vandoorn. Droop control as an alternative inertial response strategy for the synthetic inertia on wind turbines. IEEE Trans Power Syst 2015;31(2):1129-1138.

[64] Y Wang, J Meng, X Zhang, L Xu. Control of pmsg-based wind turbines for system inertial response and power oscillation damping. IEEE Trans Sustain Energy 2015;6(2):565-574.

[65] M Fischer, S Engelken, N Mihov, A Mendonca. Operational experiences with inertial response provided by type 4 wind turbines. IET Renew Power Gener 2016;10(1):17-24

[66] A Hosseinipour, H Hojabri. Virtual inertia control of PV systems for dynamic performance and damping enhancement of dc microgrids with constant power loads. IET Renew Power Gener 2017;12(4):430-438.

[67] P Tielens. Operation and control of power systems with low synchronous inertia Ph.D. thesis. KU Leuven; 2017.

[68] SI Nanou, AG Papakonstantinou, SA Papathanassiou. A generic model of two-stage grid-connected pv systems with primary frequency response and inertia emulation. Electr Power Syst Res 2015;127:186-196.

[69] J Liu, D Yang, W Yao, R Fang, H Zhao, B Wang. Pv-based virtual synchronous generator with variable inertia to enhance power system transient stability utilizing the energy storage system. Protect Control of Mod Power Syst 2017;2(1):39.

[70] ZX Tang, YS Lim, S Morris, JL Yi, PF Lyons, PC Taylor. A comprehensive work package for energy storage systems as a means of frequency regulation with increased penetration of photovoltaic systems. Int J Electr Power Energy Syst 2019;110:197-207.

[71] L Yang, Z Hu, S Xie, S Kong, W Lin. Adjustable virtual inertia control of supercapacitors in pv-based ac microgrid cluster. Electr Power Syst Res 2019;173:71-85.

[72] AG Rodriguez, AG Rodríguez, MB Payán. Estimating wind turbines mechanical constants. Proc. Int. Conf. Renewable energies and power quality. ICREPQ 07; 2007. p 27-30.

[73] J Slootweg, H Polinder, W Kling. Representing wind turbine electrical generating systems in fundamental frequency simulations. IEEE Trans Energy Convers 2003;18(4):516-524.

[74] SK Salman, AL Teo. Windmill modeling consideration and factors influencing the stability of a grid-connected wind power-based embedded generator. IEEE Trans Power Syst 2003;18(2):793-802.

[75] M Kalantar, et al. Dynamic behavior of a stand-alone hybrid power generation system of wind turbine, microturbine, solar array and battery storage. Appl Energy 2010;87(10):3051-3064.

[76] T Littler, B Fox, D Flynn. Measurement-based estimation of wind farm inertia. Power tech, 2005 IEEE Russia. IEEE; 2005. p. 1-5.

[77] G Lalor, A Mullane, M O'Malley. Frequency control and wind turbine technologies. IEEE Trans Power Syst 2005;20(4):1905-1913.

[78] J Morren, SWH de Haan, WL Kling, JA Ferreira. Wind turbines emulating inertia and supporting primary frequency control. IEEE Trans Power Syst 2006;21(1):433-434. doi:10.1109/TPWRS.2005.861956.

[79] NR Ullah, T Thiringer, D Karlsson. Temporary primary frequency control suppor by variable speed wind turbines-potential and applications. IEEE Trans Power Syst 2008;23(2):601-612.

[80] T Ackermann. Wind power in power systems. John Wiley \& Sons; 2005.

[81] JB Ekanayake, L Holdsworth, X Wu, N Jenkins. Dynamic modeling of doubly fed induction generator wind turbines. IEEE Trans Power Syst 2003;18(2):803-809.

[82] RG de Almeida, ED Castronuovo, JP Lopes. Optimum generation control in wind parks when carrying out system operator requests. IEEE Trans Power Syst 2006;21(2):718-725

[83] M Kayikçi, JV Milanovic. Dynamic contribution of DFIG-based wind plants to system frequency disturbances. IEEE Trans Power Syst 2009;24(2):859-867.

[84] L Qu, W Qiao. Constant power control of DFIG wind turbines with supercapacitor energy storage. IEEE Trans Ind Appl 2011;47(1):359-367.
[85] L Holdsworth, X Wu, JB Ekanayake, N Jenkins. Comparison of fixed speed and doubly-fed induction wind turbines during power system disturbances. IEE Proc Gener Transm Distrib 2003;150(3):343-352.

[86] A Perdana, O Carlson, J Persson. Dynamic response of grid-connected wind turbine with doubly fed induction generator during disturbances. Nordic workshop on power and industrial electronics, 1 . Citeseer; 2004. p. 1-7.

[87] L Xu, L Yao, C Sasse. Grid integration of large DFIG-based wind farms using vsc transmission. IEEE Trans Power Syst 2007;22(3):976-984.

[88] R Gagnon, G Sybille, S Bernard, D Paré, S Casoria, C Larose. Modeling and real-time simulation of a doubly-fed induction generator driven by a wind turbine. Intl. Conference on power systems transients. Canada; 2005.

[89] MFM Arani, EF El-Saadany. Implementing virtual inertia in DFIG-based wind power generation. IEEE Trans Power Syst 2013;28(2):1373-1384.

[90] L Yang, Z Xu, J Ostergaard, ZY Dong, KP Wong. Advanced control strategy of DFIG wind turbines for power system fault ride through. IEEE Trans Power Syst 2012;27(2):713-722.

[91] L Xu, P Cartwright. Direct active and reactive power control of DFIG for wind energy generation. IEEE Trans Energy Convers 2006;21(3):750-758.

[92] J Ekanayake, L Holdsworth, N Jenkins. Comparison of 5th order and 3rd order machine models for doubly fed induction generator (dfig) wind turbines. Electr Power Syst Res 2003;67(3):207-215.

[93] A Westlake, J Bumby, E Spooner. Damping the power-angle oscillations of a permanent-magnet synchronous generator with particular reference to wind turbine applications. IEE Proc Electr Power Appl 1996;143(3):269-280.

[94] D Rasolomampionona. A modified power system model for agc analysis. PowerTech, 2009 IEEE bucharest. IEEE; 2009. p. 1-6.

[95] H Bevrani, PR Daneshmand. Fuzzy logic-based load-frequency control concerning high penetration of wind turbines. IEEE Systems Journal 2012;6(1):173-180.

[96] LL Grigsby. Power system stability and control. CRC press; 2016.

[97] B Ozer, O Arikan, G Moral, A Altintas. Extraction of primary and secondary frequency control from active power generation data of power plants. Int J Electr Power Energy Syst 2015;73:16-22.

[98] C Zhao, E Mallada, F Dörfler. Distributed frequency control for stability and economic dispatch in power networks. 2015 American control conference (ACC). IEEE; 2015. p. 2359-2364.

[99] AM Ersdal, L Imsland, K Uhlen. Model predictive load-frequency control. IEEE Trans Power Syst 2016;31(1):777-785.

[100] C Zhao, U Topcu, N Li, S Low. Design and stability of load-side primary frequency control in power systems. IEEE Trans Autom Control 2014;59(5):1177-1189.

[101] SK Pandey, SR Mohanty, N Kishor. A literature survey on load-frequency control for conventional and distribution generation power systems. Renew Sustain Energy Rev 2013;25:318-334.

[102] J Li, R Xiong, Q Yang, F Liang, M Zhang, W Yuan. Design/test of a hybrid energy storage system for primary frequency control using a dynamic droop method in an isolated microgrid power system. Appl Energy 2017;201:257-269.

[103] JM Guerrero, JC Vasquez, J Matas, M Castilla, LG de Vicuna. Control strategy for flexible microgrid based on parallel line-interactive ups systems. IEEE Trans Ind Electron 2009;56(3):726-736.

[104]Continental europe operation handbook - p1, Tech. rep., European Network of Transmission System Operators for Electricity.

[105] JW Simpson-Porco, Q Shafiee, F Dörfler, JC Vasquez, JM Guerrero, F Bullo. Secondary frequency and voltage control of islanded microgrids via distributed averaging. IEEE Trans Ind Electron 2015;62(11):7025-7038.

[106] Z Miao, L Fan. Achieving economic operation and secondary frequency regulation simultaneously through feedback control. IEEE Trans Power Syst 2016;31(4):3324-3325

[107] J Tan, Y Zhang, I Krad, V Gevorgian, E Ela. Investigating power system primary and secondary reserve interaction under high wind power penetration using frequency response model. Proc. Grid future symp.; 2015. p. 1-6.

[108] M Perninge, R Eriksson. Optimal tertiary frequency control in power systems with market-based regulation. IFAC-PapersOnLine 2017;50(1):4374-4381.

[109] T Qureshi, R Alvi. A review on secondary and tertiary control structures for microgrid. 2018.

[110] W Li, P Du, N Lu. Design of a new primary frequency control market for hosting frequency response reserve offers from both generators and loads. IEEE Trans Smart Grid Sept. 2018;9(5):4883-4892.

[111] M Nedd, C Booth, K Bell. Potential solutions to the challenges of low inertia power systems with a case study concerning synchronous condensers. Universities power engineering conference (UPEC), 2017 52nd International. IEEE; 2017. p. 1-6.

[112] A Ulbig, TS Borsche, G Andersson. Analyzing rotational inertia, grid topology and their role for power system stability. IFAC-PapersOnLine 2015;48(30):541-547.

[113] A Junyent-Ferr, Y Pipelzadeh, TC Green. Blending hvdc-link energy storage and offshore wind turbine inertia for fast frequency response. IEEE Trans Sustain Energy 2015;6(3):1059-1066.

[114] R You, B Barahona, J Chai, NA Cutululis, X Wu. Improvement of grid frequency dynamic characteristic with novel wind turbine based on electromagnetic coupler. Renew Energy 2017;113:813-821.

[115] J Marcos, O Storkël, L Marroyo, M Garcia, E Lorenzo. Storage requirements for pv power ramp-rate control. Sol Energy 2014;99:28-35.

[116] NB Salim, H Aboelsoud, T Tsuji, T Oyama, K Uchida. Load frequency control of two-area network using renewable energy resources and battery energy storage system. J Electr Syst 2017;13(2).

[117] Z Zhao, H Xiao, Y Yang. Improved coordinated control strategy of hybrid energy storages in pv power smoothing. Energy Procedia 2018;145:151-156. 
[118] M Taghizadeh, M Hoseintabar, J Faiz. Frequency control of isolated wt/pv/sofc/ uc network with new control strategy for improving sofc dynamic response. Int Trans Electr Energy Syst 2015;25(9):1748-1770.

[119] S You, Y Liu, J Tan, MT Gonzalez, X Zhang, Y Zhang, et al. Comparative assessment of tactics to improve primary frequency response without curtailing solar output in high photovoltaic interconnection grids. IEEE Trans Sustain Energy April 2019;10(2):718-728.

[120] W Ziping, G Wenzhong, G Tianqi, Y Weihang, H ZHANG, Y Shijie, et al. State-of-the-art review on frequency response of wind power plants in power systems. J Modern Power Syst Clean Energy 2017;1-16.

[121] H Xin, Y Liu, Z Wang, D Gan, T Yang. A new frequency regulation strategy for photovoltaic systems without energy storage. IEEE Trans Sustain Energy 2013;4(4):985-993.

[122] H Alatrash, A Mensah, E Mark, G Haddad, J Enslin. Generator emulation controls for photovoltaic inverters. IEEE Trans Smart Grid 2012;3(2):996-1011.

[123] P Zarina, S Mishra, P Sekhar. Deriving inertial response from a non-inertial pv system for frequency regulation. Power electronics, drives and energy systems (PEDES), 2012 IEEE International conference on. IEEE; 2012. p. 1-5.

[124] P Zarina, S Mishra, P Sekhar. Photovoltaic system based transient mitigation and frequency regulation. India conference (INDICON), 2012 annual IEEE. IEEE; 2012. p. $1245-1249$.

[125] S Mishra, P Zarina, P Sekhar. A novel controller for frequency regulation in a hybrid system with high pv penetration. Power and energy society general meeting (PES), 2013 IEEE. IEEE; 2013. p. 1-5.

[126] C Rahmann, A Castillo. Fast frequency response capability of photovoltaic power plants: the necessity of new grid requirements and definitions. Energies 2014;7(10):6306-6322.

[127] P Zarina, S Mishra, P Sekhar. Exploring frequency control capability of a pv system in a hybrid pv-rotating machine-without storage system. Int J Electr Power Energy Syst 2014;60:258-267.

[128] P Moutis, A Vassilakis, A Sampani, N Hatziargyriou. Dc switch driven active power output control of photovoltaic inverters for the provision of frequency regulation. IEEE Trans Sustain Energy 2015;6(4):1485-1493.

[129] L Xiong, Y Li, Y Zhu, P Yang, Z Xu. Coordinated control schemes of super-capacitor and kinetic energy of DFIG for system frequency support. Energies 2018;11(1):103.

[130] C Jauch, S Hippel. Hydraulic-pneumatic flywheel system in a wind turbine rotor for inertia control. IET Renew Power Gener 2016;10(1):33-41.

[131] P Moutis, E Loukarakis, S Papathanasiou, ND Hatziargyriou. Primary load-frequency control from pitch-controlled wind turbines. PowerTech, 2009 IEEE bucharest. IEEE; 2009. p. 1-7.

[132] H Ma, B Chowdhury. Working towards frequency regulation with wind plants: combined control approaches. IET Renew Power Gener 2010;4(4):308-316.

[133] P Moutis, SA Papathanassiou, ND Hatziargyriou. Improved load-frequency control contribution of variable speed variable pitch wind generators. Renew Energy 2012;48:514-523.

[134] A Žertek, G Verbič, M Pantoš. Optimised control approach for frequency-contro contribution of variable speed wind turbines. IET Renew Power Gener 2012;6(1):17-23.

[135] LM Castro, CR Fuerte-Esquivel, JH Tovar-Hernández. Solution of power flow with automatic load-frequency control devices including wind farms. IEEE Trans Powe Syst 2012;27(4):2186-2195.

[136] K Vidyanandan, N Senroy. Primary frequency regulation by deloaded wind turbines using variable droop. IEEE Trans Power Syst 2013;28(2):837-846.

[137] S Wang, K Tomsovic. A novel active power control framework for wind turbine generators to improve frequency response. IEEE Trans Power Syst Nov. 2018;33(6):6579-6589.

[138] X Zhang, X Zha, S Yue, Y Chen. A frequency regulation strategy for wind power based on limited over-speed de-loading curve partitioning. IEEE Access 2018;6:22938-22951.

[139] NA Janssens, G Lambin, N Bragard. Active power control strategies of DFIG wind turbines. Power tech, 2007 IEEE lausanne. IEEE; 2007. p. 516-521.

[140] G Ramtharan, N Jenkins, J Ekanayake. Frequency support from doubly fed induction generator wind turbines. IET Renew Power Gener 2007;1(1):3-9.

[141] AS Alsharafi, AH Besheer, HM Emara. Primary frequency response enhancement for future low inertia power systems using hybrid control technique. Energies 2018;11(4):699.

[142] MF Arani, YAI Mohamed. Dynamic droop control for wind turbines participating in primary frequency regulation in microgrids. IEEE Trans Smart Grid Nov. 2018;9(6):5742-5751.

[143] P Lertapanon, W Wangdee. Analysis and modeling of wind turbine generators considering frequency controls. Electrical engineering congress (iEECON), 2017 International. IEEE; 2017. p. 1-4

[144] L Huang, H Xin, L Zhang, Z Wang, K Wu, H Wang. Synchronization and frequency regulation of DFIG-based wind turbine generators with synchronized control. IEEE Trans Energy Convers 2017;32(3):1251-1262.

[145] M Deepak, RJ Abraham, FM Gonzalez-Longatt, DM Greenwood, H-S Rajamani. A novel approach to frequency support in a wind integrated power system. Renew Energy 2017;108:194-206.
[146] H Ye, W Pei, Z Qi. Analytical modeling of inertial and droop responses from a wind farm for short-term frequency regulation in power systems. IEEE Trans Power Syst 2016;31(5):3414-3423.

[147] F Gonzalez-Longatt, E Chikuni, W Stemmet, K Folly. Effects of the synthetic inertia from wind power on the total system inertia after a frequency disturbance. Power engineering society conference and exposition in Africa. Citeseer; 2012. p. 9-13.

[148] A Bonfiglio, M Invernizzi, A Labella, R Procopio. Design and implementation of a variable synthetic inertia controller for wind turbine generators. IEEE Trans Power Syst Jan. 2019;34(1):754-764.

[149] K Liu, Y Qu, H-M Kim, H Song. Avoiding frequency second dip in power unreserved control during wind power rotational speed recovery. IEEE Trans Power Syst 2018;33(3):3097-3106.

[150] M Dreidy, H Mokhlis, S Mekhilef. Inertia response and frequency control techniques for renewable energy sources: a review. Renew Sustain Energy Rev 2017;69:144-155.

[151] F Díaz-González, M Hau, A Sumper, O Gomis-Bellmunt. Participation of wind power plants in system frequency control: review of grid code requirements and control methods. Renew Sustain Energy Rev 2014;34:551-564.

[152] GC Tarnowski, PC Kjar, PE Sorensen, J Ostergaard. Variable speed wind turbines capability for temporary over-production. Power \& energy society general meeting, 2009. PES'09. IEEE. IEEE; 2009. p. 1-7.

[153] P-K Keung, P Li, H Banakar, BT Ooi. Kinetic energy of wind-turbine generators for system frequency support. IEEE Trans Power Syst 2009;24(1):279-287.

[154] S El Itani, UD Annakkage, G Joos. Short-term frequency support utilizing inertial response of DFIG wind turbines. Power and energy society general meeting, 2011 IEEE. IEEE; 2011. p. 1-8.

[155] AD Hansen, M Altin, ID Margaris, F Iov, GC Tarnowski. Analysis of the short-term overproduction capability of variable speed wind turbines. Renew Energy 2014;68:326-336.

[156] F Hafiz, A Abdennour. Optimal use of kinetic energy for the inertial support from variable speed wind turbines. Renew Energy 2015;80:629-643.

[157] M Kang, K Kim, E Muljadi, J-W Park, YC Kang. Frequency control support of a doubly-fed induction generator based on the torque limit. IEEE Trans Power Syst 2016;31(6):4575-4583.

[158] A Fernández-Guillamón, J Villena-Lapaz, A Vigueras-Rodríguez, T García-Sánchez, Á Molina-García. An adaptive frequency strategy for variable speed wind turbines: application to high wind integration into power systems. Energies 2018;11(6):1-21.

[159] A Fernández-Guillamón, A Vigueras-Rodríguez, E Gómez-Lázaro, Á Molina-García. Fast power reserve emulation strategy for vswt supporting frequency control in multi-area power systems. Energies 2018;11(10). doi:10.3390/en11102775 http: //www.mdpi.com/1996-1073/11/10/2775.

[160] ID Margaris, SA Papathanassiou, ND Hatziargyriou, AD Hansen, P Sorensen. Frequency control in autonomous power systems with high wind power penetration. IEEE Trans Sustain Energy 2012;3(2):189-199.

[161] L-R Chang-Chien, W-T Lin, Y-C Yin. Enhancing frequency response control by DFIGs in the high wind penetrated power systems. IEEE Trans Power Syst 2011;26(2):710-718.

[162] F Wilches-Bernal, JH Chow, JJ Sanchez-Gasca. A fundamental study of applying wind turbines for power system frequency control. IEEE Trans Power Syst 2016;31(2):1496-1505.

[163] W Zhang, K Fang. Controlling active power of wind farms to participate in load frequency control of power systems, IET Generation. Transm Distrib 2017;11(9):2194-2203.

[164] C Su, Z Chen. Influence of wind plant ancillary frequency control on system smal signal stability. Power and energy society general meeting, 2012 IEEE. IEEE; 2012. p. 1-8.

[165] M Hwang, E Muljadi, J-W Park, P Sørensen, YC Kang. Dynamic droop-based inertial control of a doubly-fed induction generator. IEEE Trans Sustain Energy 2016;7(3):924-933.

[166] J Van de Vyver, JD De Kooning, B Meersman, L Vandevelde, TL Vandoorn. Droop control as an alternative inertial response strategy for the synthetic inertia on wind turbines. IEEE Trans Power Syst 2016;31(2):1129-1138.

[167] M Kang, J Lee, K Hur, SH Park, Y Choy, YC Kang. Stepwise inertial control of doubly-fed induction generator to prevent a second frequency dip. J Electr Eng Technol 2015;10(6):2221-2227.

[168] R You, B Barahona, J Chai, NA Cutululis. Frequency support capability of variable speed wind turbine based on electromagnetic coupler. Renew Energy 2015;74:681-688.

[169] Z Zhang, Y Wang, H Li, X Su. Comparison of inertia control methods for DFIG-based wind turbines. ECCE Asia Downunder (ECCE Asia), 2013 IEEE. IEEE; 2013. p. 960-964.

[170] Z-S Zhang, Y-Z Sun, J Lin, G-J Li. Coordinated frequency regulation by doubly fed induction generator-based wind power plants. IET Renew Power Gener 2012;6(1):38-47. 